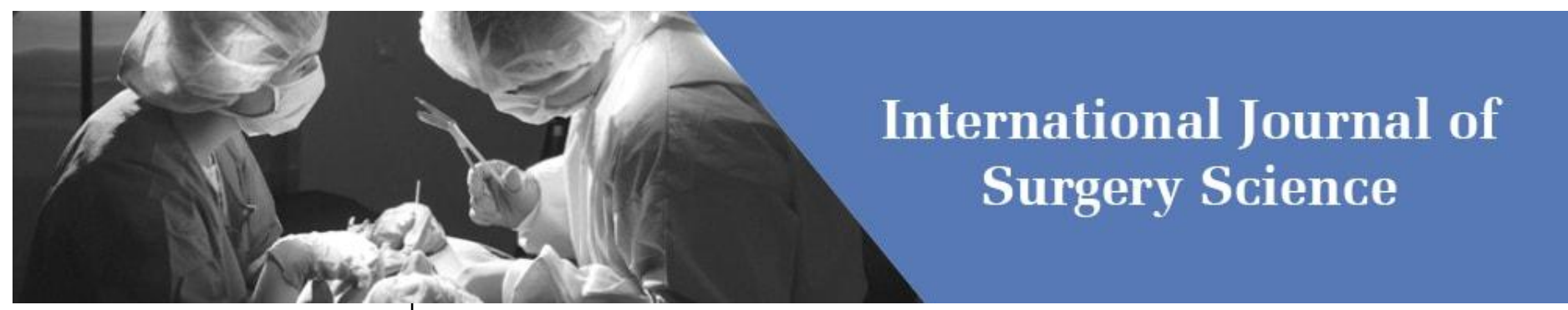

E-ISSN: 2616-3470

P-ISSN: 2616-3462

(C) Surgery Science

www.surgeryscience.com

$2020 ; 4(3): 208-210$

Received: 04-05-2020

Accepted: 07-06-2020

Dr. Arjun A

Assistant Professor of surgery

Ramaiah medical college,

Bengaluru, Karnataka, India
Corresponding Author: Dr. Arjun A

Assistant Professor of surgery

Ramaiah medical college,

Bengaluru, Karnataka, India

\section{To study the prevalence of Helicobacter pylori in patients with dyspepsia undergoing upper gastrointestinal endoscopy}

\section{Dr. Arjun A}

DOI: https://doi.org/10.33545/surgery.2020.v4.i3d.492

\section{Abstract}

Introduction: Acid peptic disease comprises of a wide spectrum of diseases, which cause considerable morbidity. Helicobacter pylori, a curved rod shaped bacterium, has been consistently associated with patients suffering from acid peptic diseases, more in ulcer disease than in on ulcer disease. Due to this high association, it is now believed that Helicobacter pylori plays an important role in the etiopathogenesis of acid peptic disease.

Methodology: 194cases of dyspepsia were studied clinically as per the proforma over a period of one year from August 2017 to September 2018 in Saptagiri institute of medical sciences \& research, Bangalore.

Results: Out of 194 patients, there were 122 male patients and 72 female patients, age ranging from 15 years to 60 years (Mean-41.8).

Keywords: HPE-Histopathological Examination, HP-Helicobacter pylori, PA-Painabdomen

\section{Introduction}

Acid peptic disease comprises of a wide spectrum of diseases, which cause considerable morbidity. Helicobacter pylori, a curved rod shaped bacterium, has been consistently associated with patients suffering from acid peptic diseases, more in ulcer disease than in non-ulcer disease. Due to this high association, it is now believed that Helicobacter pylori plays an important role in the etiopathogenesis of acid peptic disease. Several studies have revealed the association of Helicobacter pylori in 70-75 Percent of patients with dyspepsia. Endoscopic studies have shown that, Helicobacter pylori is found in 80-100 percent of patients with duodenalulcers and 60-75 percent of patients with gastric ulcers. Amid these profound variations proposed by many workers in the previous studies, we have attempted to study the prevalence of Helicobacterpy lori in patients undergoing upper gastro-intestinal endoscopy at our hospital and its association with acid-peptic disease.

\section{Aims of the study}

1. To study the prevalence of helicobacter pylori in patients with dyspepsia undergoing upper gastrointestinal endoscopy.

2. To study the association of helicobacter pylori with acid peptic diseases.

\section{Methodology}

194cases of dyspepsia were studied clinically as per the proforma over a period of one year from August 2017 to September 2018 in Saptagiri institute of medical sciences \& research, Bangalore. The inclusion and exclusion criteria's were as follows;

\section{Inclusion criteria}

1. Patients between15-60years of age.

2. Patients having chronic upper abdominal pain.

3. Patients showing symptoms of dyspepsia.

4. Patients diagnosed as having chronic gastritis, gastric / duodenal ulcers on gastroduodenoscopy. 


\section{Exclusion criteria}

1. Patientsbelow15yearsandabove60yearsofage.

2. Pregnant and Lactating women.

3. On Proton-pump inhibitors.

4. Patients who are known cases of chronic pancreatitis.

5. Patients on NSAID's for more than one month duration.

6. Patients who have received Anti-Helicobacter pylori treatment.

7. Patients with oesophageal growths on endoscopy

8. Unwilling or unfit patients for gastroscopy.

On entering the oesophagus, anylesions/ growths in the oesophagus were looked for. Cases of oesophageal carcinomas were excluded from the study as per the exclusion criteria. On entering the stomach, presence of any ulcers [Fig-1]or growths[Fig-2]was looked for

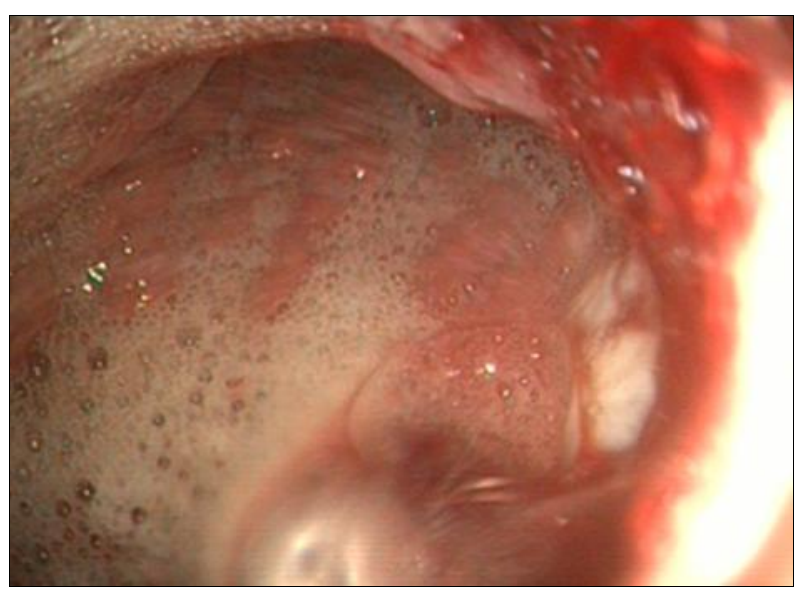

Fig 1: Endoscopic view of a gastric ulcer

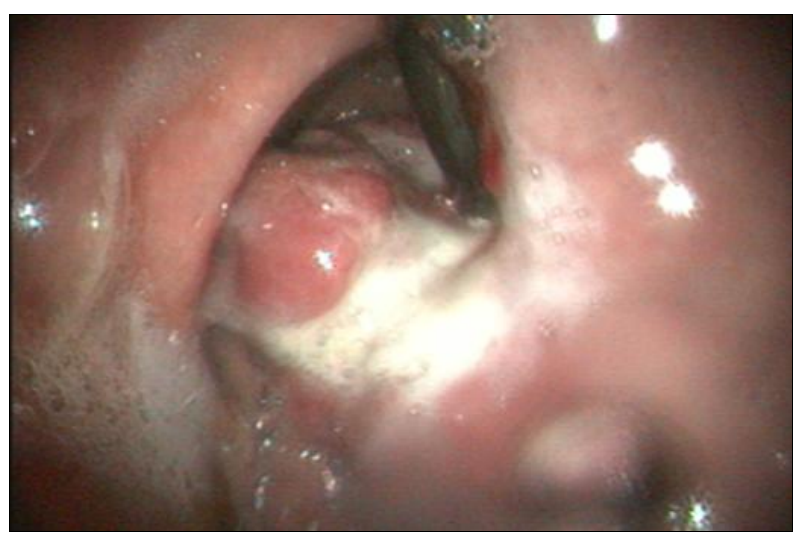

Fig 2: Endoscopic view of a gastric ulceroproliferative growth.

\section{Results}

Out of 194 patients, there were 122 male patients and 72 female patients, age ranging from15years to 60years (Mean-41.8). Out of 194 patients, 86 patients were diagnosed to have been infected with Helicobacter pylori (44.32\%).

All these patients presented to our hospital with upper abdominal pain or discomfort. 48patients presented with nausea or vomiting out of which 19 had Helicobacter pylori infection.12patients had haematemesis, out of which 5patients were positive for Helicobacter pylori infection.9 patients had malena out of which 6turned out to be Helicobacter pylori positive.10patients had loss of weight and/or appetite on presentation of them,3patients were positive for Helicobacter pylori on examination of these patients, 30patients were anaemic out of whom16patients were positive for Helicobacter pylori of these 194patients, 150 patients had epigastric tenderness on palpation and 3patients had an epigastric mass palpable of these 150patients, 76patients were tested positive for Helicobacter pylori and of those 3 patients, who had an epigastric mass, only 1 patient was positive for Helicobacter pylori. [Table-1], [Graph1]

Table 1: Prevalence of Helicobacter pylori in various clinical presentations in patients with dyspepsia

\begin{tabular}{|c|c|c|c|}
\hline Clinical Presentation & Number of Cases & $\begin{array}{c}\text { H. pylori } \\
\text { Positive }\end{array}$ & Percentage \\
\hline Abdominal pain / discomfort & 194 & 86 & 44.32 \\
\hline Nausea/ Vomiting & 48 & 19 & 39.58 \\
\hline Haematemesis & 12 & 5 & 41.66 \\
\hline Malena & 9 & 6 & 66.67 \\
\hline Loss of Weight/Appetite & 10 & 3 & 30.00 \\
\hline Anaemia & 30 & 16 & 53.33 \\
\hline Epigastricmass & 3 & 1 & 33.33 \\
\hline Epigastric tenderness & 150 & 76 & 50.67 \\
\hline
\end{tabular}

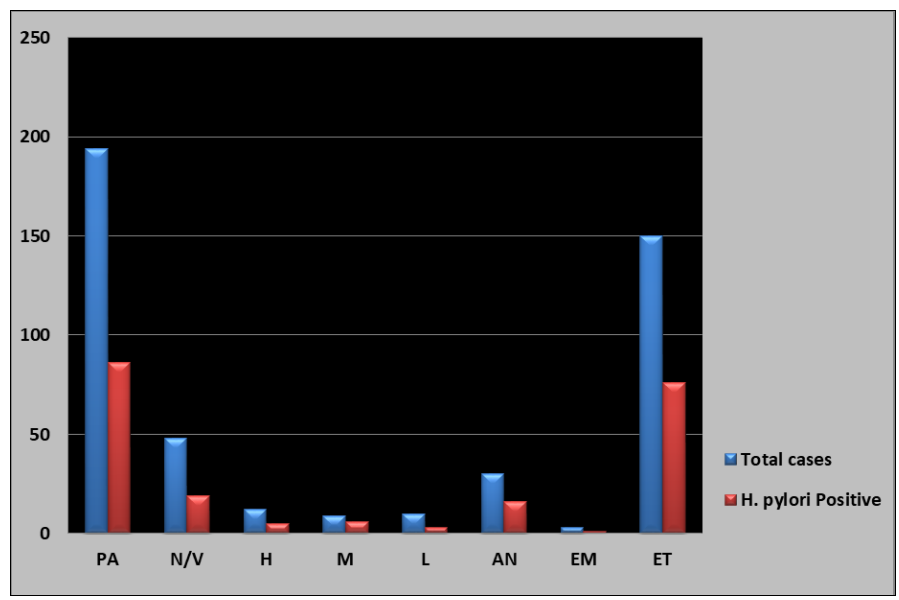

Graph 1: Prevalence of helicobacter pylori in various clinical presentations of dyspepsia

- $\quad \mathrm{PA}$ - Pain abdomen

- N/V - Nausea/ vomiting

- $\mathrm{H}$ - Haematemesis

- M-Malena

- L - Loss of weight/ appetite

- AN - Anaemia

- $\quad$ EM - Epigastric Mass

- $\quad$ ET - Epigastric Tenderness

\section{Discussion}

After the discovery of Helicobacter pylori by Marshall and Warrenin1983, many studies were conducted to confirm the association of Helicobacter pylori with various acid-peptic diseases and carcinoma stomach. The following observations were made:

1. The treatment of Helicobacter pylori led to the reversal of gastritis in patients with chronic non-specific gastritis.

2. The eradication of Helicobacter pylori decreases there lapse of peptic ulcer to $1 \%-3 \%$ when compared to $80 \%$ relapses in patients with persistent Helicobacter pylori infections after medical management.

Inspite of the above findings, the cause-and effect relationship between Helicobacter pylori and peptic ulcer disease is not proved and further-more many people infected with Helicobacter pylori did not develop peptic ulceration.

The association of Helicobacterpylori with non-ulcer 
dyspepsiais controversial. The rapeutictrial sinnon-ulcer dyspepsia patients with Helicobacter pylori infection produced conflicting results.

Thus, at this stage in the history of acid-peptic disease and its association with Helicobacter pylori, the causation or association between. The two is still unclear. In case of non-ulcer dyspepsia this is still more augmented by the conflicting results produced by the workers world-wide.

\section{Conclusion}

This was a prospective study conducted to determine the role of Helicobacter pylori in acid-pepticdiseases. This study design was based on clinical study and endoscopic biopsy of gastric mucosa (and duodenal mucosa whenever necessary) in 194 patients with a history of dyspepsia. Endoscopy confirmed the diagnosis. H\&E and Giemsa staining were conducted on endoscopy biopsy specimens and Helicobacter pylori positivity was based on histopathological examination. From the present study it is evident that,

1. There was no specific symptom attributable to H. pylori infection.

2. Helicobacter pylori infection is more common in males than females.

3. Helicobacter pylori is consistently associated with peptic ulcer disease than non-ulcerdyspepsia, which is in broad agreement with the studies done earlier. Thus we conclude that, Helicobacter pylori infection may have a role in the etiopathogenesis of peptic ulcer disease.

4. There appears to be no significant association between Helicobacter pylori infection and unexplained dyspepsia. This finding does not exclude the possibility that a small undefined subset of infected individuals will have symptoms induced by the infection, but only larger and randomized trials will be able to establish this.

5. Hence, we recommend eradication of the bacteria only in patients positive for the bacterium, who have peptic ulceration. We believe in, Peter C Robin's dictum: "If a person with peptic ulcer disease is shown to have Helicobacter pylori, then eradication is indicated".

\section{References}

1. Freston JW. "Helicobacterpylori-negative pepticulcers: frequency and implications for management. "Journal of Gastroenterology. 2000; 35(12):29-32.

2. Kidd M, Louw JA etal. "Helicobacter pyloriin Africa: Observations on an 'Enigma with in an enigma." Journal of Gastroenterology\& Hepatology. 1999; 14(9):851-8.

3. Jain A, Buddhiraja $\mathrm{S}$ et al. "Risk factors for duodenalulcers in North India." Tropical Gastroenterology. 1999; 20(1):3639.

4. Perri F, Festa Vetal. "Dyspepsiaand Helicobacter pylori infection: Aprospective multi centric observational study." Digestive and Liver Disease. 2003; 35(3):157-64.

5. Marshall BJ, Warren JR. "Un identified curved bacilliinthestomach of patients with Gastritis and pepticulceration." The Lancet. 1984; 16:1311-15. 